Int. J. Electrochem. Sci., 13 (2018) 2090 - 2101

\title{
Synergistic Behavior of Mixed Monolayer/Mixed Micelle Formation between Cationic Monomeric and Dimeric Surfactants with PEO-PPO-PEO Triblock Copolymer
}

\author{
Naved Azum ${ }^{1, *}$, Andleeb Z. Naqvi ${ }^{2}$ \\ ${ }^{1}$ Chemistry Department, Faculty of Science, King Abdulaziz University, Jeddah 21589, Saudi Arabia \\ ${ }^{2}$ Department of Chemistry, Faculty of Science, Aligarh Muslim University, Aligarh, India \\ *E-mail: navedazum@gmail.com
}

doi: $10.20964 / 2018.02 .74$

Received: 19 October 2017 / Accepted: 18 December 2017 / Published: 28 December 2017

\begin{abstract}
The micellar and surface properties of PEO-PPO-PEO triblock copolymer (Pluronic F-127) with cationic monomeric (hexadecyltrimethylammonium bromide), and gemini or dimeric (Pentanediyl-1, 5-bis (dimethylcetylammonium bromide)) surfactants was investigated using surface tension and conductivity measurements in aqueous solution. Various micellar, interfacial and thermodynamic parameters were evaluated. All the mixtures of binary systems show synergism. The synergistic interactions are found to be more with dimeric surfactant. The copolymer contribution in mixed micelles also increases with gemini surfactant.
\end{abstract}

Keywords: Triblock co-polymer, Gemini surfactant, Conventional surfactant, Mixed micelle, Synergism

\section{$\underline{\text { FULL TEXT }}$}

(C) 2018 The Authors. Published by ESG (www.electrochemsci.org). This article is an open access article distributed under the terms and conditions of the Creative Commons Attribution license (http://creativecommons.org/licenses/by/4.0/). 